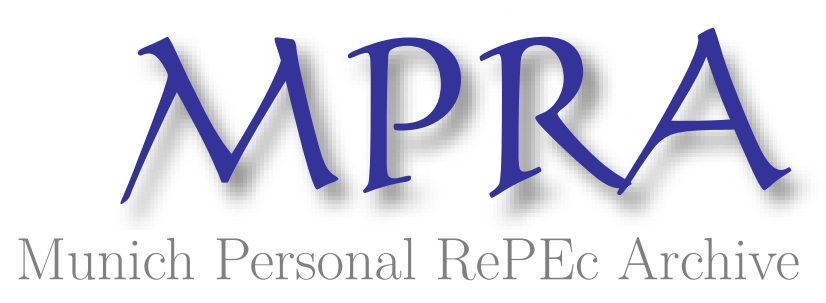

\title{
Productive Public Expenditure in a New Economic Geography Model
}

Commendatore, Pasquale and Kubin, Ingrid and Petraglia, Carmelo

Economic Growth: Insitutional and Social Dynamics Working Papers Series

April 2007

Online at https://mpra.ub.uni-muenchen.de/5824/

MPRA Paper No. 5824, posted 20 Nov 2007 09:09 UTC 


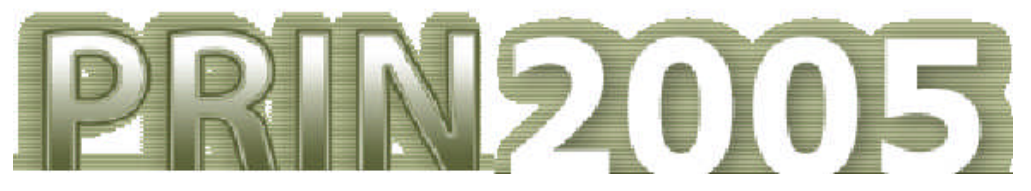

\title{
Economic Growth: Institutional and Social Dynamics PROGRAMMI DI RICERCA SCIENTIFICA DI RILEVANTE INTERESSE NAZIONALE 2005
}

\author{
WORKING PAPER SERIES
}

\section{Productive Public Expenditure in a New Economic Geography Model}

\author{
Pasquale Commendatore \\ Department of Economic Theory \\ and Applications \\ University of Naples \\ "Federico II", Italy \\ commenda@unina.it
}

\author{
Ingrid Kubin \\ Department of Economics \\ Vienna University of \\ Economics and Business \\ Administration, Austria \\ ingrid.kubin@wu- \\ wien.ac.at
}

\author{
Carmelo Petraglia \\ Department of Economics \\ University of Naples \\ "Federico II", Italy \\ petragli@unina.it
}

Working Paper 016

April 2007

\begin{abstract}
This Working Papers Series aims to facilitate the dissemination of the research conducted by the members of the research group "Economic Growth: Institutional and Social Dynamics", financed by the Italian Ministry of Education, University and Research in 2005. The series proposes to focus on the complex interplay of institutional and social dynamics as a key to understand the process of economic growth on both theoretical and empirical grounds, and to represent a forum for constructive confrontation of different schools of thought on these topics.
\end{abstract}




\title{
Productive Public Expenditure in a New Economic Geography Model
}

\author{
Pasquale Commendatore \\ Ingrid Kubin \\ Carmelo Petraglia \\ Working Paper 016
}

\begin{abstract}
We pursue the question of whether and how differences in productive public expenditure impacts on industrial location. The public sector, which operates with a balanced budget constraint, finances its expenditures taxing residents' income. Since the introduction of productive public expenditure and taxation affects in opposite direction the industrial location, results are very sensitive to the specific parameter constellation assumed. That is, it is not straightforward that following an increase in productive public expenditure in a region, that region will necessarily enjoy stronger agglomeration. As a major contribution to the literature, our approach considers jointly two effects arising from public policy decisions on expenditure: the demand effect and the productivity effect. The interplay of these two effects determines the final impact of an increase in productive public spending in one region on the spatial distribution of firms. Furthermore, the latter result is influenced by the way in which tax payers of the two regions contribute to the financing of productive public expenditure. Finally, in the case of symmetric regions, the impact on welfare of an increase in productive public services is found to be positive under certain conditions.
\end{abstract}

JEL CODES: F20, H5, R12

KEYWORDS: economic geography, public expenditure, footloose capital. 


\section{Introduction}

In the models of the New Economic Geography (henceforth NEG), countries or regions are separated by transport costs and agglomeration is brought about by factor mobility due to differences in regional economic incentives. Because of decreasing average costs in production, factor rewards are the higher, the higher the local demand is. A high share in total expenditure thus leads to an even higher share in industrial capital. This indicates obvious points at which public policy, i.e. taxation and public expenditures can affect this mechanism:

1) Factor mobility motivated by differences in net factor income is directly affected by tax policy. Most studies of public policy within the NEG take this aspect on board (e.g. the literature on tax competition: Baldwin and Krugman, 2004 and Borck and Pflüger, 2006, among the others; the literature on regional subsidies: Commendatore et al., 2005 and Dupont and Martin, 2006).

2) The provision of public goods can also impact upon the migration decision (see for this aspect Baldwin et al., 2003). However, public policy is also a central factor determining both the level and the composition of local demand. In a framework with decreasing average costs this directly influences gross factor rewards. Income taxes change the disposable income and thus private expenditures; public expenditures are typically different from the private ones as far as their regional and sectoral structure is concerned. Trionfetti (1997) and Brülhart and Trionfetti (2004) study the former aspect. The latter is at the core of Commendatore and Kubin (2006) where it is explored whether sectoral differences in public policy may lead to industry agglomeration.

3) Transport costs can be reduced by public expenditures for infrastructure (see Martin and Rogers, 1995; Martin, 1999).

4) Public expenditure can also affect factor rewards in a region via its effect upon productivity. This aspect has been also studied to some extent in the NEG models (Brakman et al., 2002).

In our paper, we pursue the question of whether and how differences in productive public expenditure may impact on industrial location. We assume that the government in order to improve labour productivity in the industrial sector provides productive public services (generic: health 
services, schooling; and/or specific: training on the job) ${ }^{1}$ financing their production taxing residents' income.

While the (positive or negative) impact of government expenditures on location via the local consumption of manufactured goods - what we will refer to as the "demand effect" of government expenditures - and via the productivity of the local industrial sector - the "productivity effect" have been kept separate so far in the literature, our framework will allow us to account for their joint consideration.

Since the introduction of productive public expenditures and taxation may affect in opposite directions the location of industrial activity, results are very sensitive to the specific assumptions. That is, it is not straightforward that following an increase in productive public expenditure in a region, that region will necessarily enjoy stronger agglomeration.

Finally, by separating the investment goods sector from the consumer goods manufacturing sector we are able to capture the effect of public expenditure on the long-run level of capital stock of the overall economy.

The remained of the paper is organized as follows. Section 2 assesses the scarce literature on public expenditure and NEG. Section 3 presents the main assumptions of the model. In section 4, we characterize the short-run equilibrium. Section 5 is devoted to the long-run equilibrium and to the study of the impact of public expenditure on industrial location. Section 6 analises the welfare impact of public policy and section 7 concludes.

\section{Related literature}

In the standard Core-Periphery (CP) model (Krugman, 1991) it is assumed that mobile workers spend their incomes locally and the spatial distribution of industrialized activities is determined by the interplay of agglomeration and dispersion forces. Imperfectly competitive firms tend to locate in the biggest market, enforcing the so-called "home market" effect which leads to agglomeration. The "cost of living" effect - goods are cheaper in regions with higher concentration of industrial firms -

\footnotetext{
${ }^{1}$ Generally speaking, EU regional policies favour both business incentives (for instance, by providing financial subsidies to private investment and, as a consequence, boosting capital accumulation) and measures aimed at improving the social-economic environment. Within the latter, productive public services are provided in order to enhance labour productivity in less developed regions in the view that the improving of the environment is a pre-requisite of capital accumulation in less developed areas.
} 
also favors agglomeration. ${ }^{2}$ On the other hand, the market-crowding or competition effect - the presence of an increasing number of competing firms lower retail sales and wages - favors dispersion.

The standard result of the model is that, at a sufficiently low level of trade $\operatorname{costs}^{3}-$ the so-called "break point" -, when a migration shock - driven by real wage differentials - occurs, agglomeration forces overpower dispersion ones in such a way to end up with the concentration of all industry in one region. As a result, complete agglomeration in one region is a stable equilibrium.

The impact of public expenditures on the location of industry has been studied within the standard CP model (Trionfetti, 1997), as well as within two variants of the CP model, namely, the Footloose Capital (FC) model (Martin and Rogers, 1995; Martin and Ottaviano, 1999; Martin, 1999) and the Footloose Entrepreneur (FE) model (Brakman et al., 2002).

The channels through which public expenditures may affect industrial location differ according to both their source of financing and destination. As for the definition of the tax base, the assumption of non taxed mobile factors implies that the migration choice is independent of taxation. Similarly, regardless the degree of mobility of the taxed factor, if taxes are levied under the residence principle, taxation will not affect the migration choice. As for the destination of public expenditures, the distinction between productive and unproductive use matters, defining the latter as any form of public resources entering private production technologies.

Trionfetti (1997) adds public expenditures to a standard CP model providing an additional channel to the demand-linked effect, leading to a stable equilibrium with partial agglomeration. The main focus is on public consumption and the modeling of public finance is characterized by two main assumptions. First, the government is assumed to spend tax revenues on consumption goods which are destroyed after the purchase, i.e. they are not offered as public goods by the government. This assumption is made in order to isolate the demand effect of public expenditure, at the cost of neglecting further effects which could arise from alternative uses of the goods purchased by the government. Second, workers in the manufacturing sector are not taxed. This makes the migration choice of the mobile factor independent of taxation.

Government expenditure behavior is modeled under two public procurement regimes: the "domestic procurement" regime and the "liberalized procurement" regime. Under the "domestic procurement"

\footnotetext{
2 The market access and cost of living effects are also called demand-linked and cost-linked effects, or backward and forward linkages.

3 In NEG models, integration is usually modelled as a fall in transport costs.
} 
regime the government purchases only domestic goods fixing the level of public expenditures and its allocation between domestic manufacturing and agricultural goods. Under the "liberalized procurement" regime the government controls a further policy instrument deciding also the geographical allocation of public expenditures. Intuitively, additional public demand for manufacturing goods increases local demand. This creates a new demand-linked effect in the model which can, under certain conditions, dominate all the others, leading to stable equilibria with no catastrophic agglomeration. As a policy implication, public consumption is an effective instrument that can be used to influence industrial location, regardless the level of economic integration.

Martin and Rogers (1995) develop a FC model in which public policy plays a role in facilitating trade both within and across regions. The FC model departs from the CP model for two crucial assumptions: a fixed capital requirement for each variety of the differentiated good and workers international immobility. In contrast with Krugman (1991), the mobile factor (capital) earnings are repatriated and spent where the capital owner reside. Therefore the typical CP feature of demandlinked circular causality - production changes brought about by factor movements yield expenditure switching that in turn generate further production changes - does not arise. Furthermore, since costs-of-living are irrelevant to the production location decisions of capitalists, the cost-linked circular causality of the CP model - shifts in production alter prices inducing workers migration with further production shifting - is eliminated. Hence, the CP outcome of catastrophic agglomeration in one region is ruled out; however, agglomeration still occurs due the working of the home market effect.

An improvement in domestic (international) infrastructures is modeled as a reduction in transaction costs within (across) regions. Hence, public infrastructures are viewed as any publicly provided "good, facility or institution which facilitates the juncture between production and consumption" (Martin and Roger, 1995, p. 336), affecting the actual amount of output that reaches the consumer. ${ }^{4}$ In this view, public infrastructure and services affect industrial location through demand, while neither domestic nor international public infrastructures are assumed to affect the production function, that is, any impact on factors' productivity is neglected.

Given this assumptions, better domestic infrastructures imply higher demand and lower prices for industrial goods produced in the region, thus attracting mobile capital. When regions are integrated, differentials in terms of domestic infrastructures drive the relocation of capital, with firms tending

\footnotetext{
4 The authors distinguish infrastructures that can facilitate domestic trade - such as, law and contract enforcement of telecommunication networks, public administration and, in general, intra-regional transport infrastructure - and those that facilitate trade among regions, such as the international communication and transportation systems.
} 
to locate in regions with better infrastructures. Furthermore, a higher level of international infrastructures tends to magnify such a relocation process. Hence, regional policies aimed at improving domestic infrastructure in poorer regions favor the relocation of industrial firms in these regions. On the other hand, improvements in international infrastructures lead to less concentration in poorer regions.

Brakman et al. (2002) introduce the government sector in the FE model developed by Forslid (1999), Ottaviano (2001) and Forslid and Ottaviano (2003), assessing the effectiveness of public spending as an instrument for locational competition across regions. The crucial assumption in the FE model is that producing a new manufactured variety requires one unit of mobile human capital (one entrepreneur). Contrary to the FC model, the mobile factor and its owner move together, which implies demand linked-circular causality. Furthermore, the attractiveness of one region as compared to the other is judged on the basis of real rewards paid to the mobile factor, thus leading to costlinked circular causality.

In the model by Brakman et al. (2002), the total amount of capital in each region is defined by the sum of "public" and "market" capital, with the government assumed to produce public goods by means of the former, while manufactures use the latter. The provision of public goods - financed by a uniform income tax rate - enhances both fixed and variable costs of manufacturing firms. Since public goods also enter the utility function of agents, the location decision of capital owners involves, in addition to price levels, tax rates and factors rewards, the relative size of the public goods sector. As a main conclusion, it is shown that local governments can change the equilibrium between agglomeration and dispersion forces, as the introduction of public goods fosters agglomeration. Since the attractiveness of locations for footloose entrepreneurs is influenced by its endowment of public goods, depending on the share of total regional capital used to produce public goods, a periphery can turn into a core and vice versa.

In what follows we adopt a special variant of the Footloose Capital (FC) model known as the Constructed Capital (CC) model (Baldwin, 1999; Baldwin et al., 2003). With mobile capital the CC model works similarly to a FC model with the additional feature of creation and destruction/depreciation of capital goods. ${ }^{5}$ In such a model, government productive expenditure affects not only the location of manufacture but also the long-run level of the capital stock.

\footnotetext{
5 The CC model with immobile capital preserves features otherwise lost in the FC model, that is demand-linked circular causality - production shifting brings about capital construction / destruction that in turn gives rise to
} 


\section{The basic framework}

There are two trading regions - North $(N)$ and South $(S)$ - each with three sectors: the agricultural sector $(A)$, the consumer goods manufacturing sector $(M)$ and the investment goods sector $(I)$. There are two factors of production capital $(K)$ and labour $(L) . K$ is mobile between regions whereas $L$ is interregionally immobile but freely moves between sectors. ${ }^{6}$

\section{Agriculture}

The market for the homogeneous agricultural good is perfectly competitive. The technology available to each agricultural firm is such that 1 unit of $L$ yields 1 unit of output. Under the assumption of perfect competition, the price of the agricultural good corresponds to $p_{A}=w_{A}$. Since neither region has enough workers to satisfy the total demand of both regions for the agricultural product, both regions always engage in agricultural production - the so-called "no-black hole condition".

\section{Manufacturing}

Manufacturing involves Dixit-Stiglitz monopolistic competition. The assumption of increasing returns requires two factors of production. Each manufacturer requires a fixed input of 1 unit of capital to operate (that is, the "licence" needed to create a new firm) and has a constant labour requirement $a_{M}$ for each unit of the product. Total cost of producing $x_{i}$ units of a specific good $i$ are:

$$
T C\left(x_{i}\right)=F+w_{M} a_{M} x_{i}
$$

where $F$ corresponds to the fixed cost necessary to activate the production of $i$ (that is, $F$ is the price of a unit of capital), $w_{M}$ is the nominal wage rate in manufacturing and $x_{i}$ is the total output of industry $i$.

Given the consumers' preference for variety and the increasing returns, a firm would always produce a variety different from the varieties produced by other firms. Furthermore, since 1 unit of

expenditure shifting and further production shifting - and complete agglomeration in one region (see Baldwin et al., 2003, p. 137).

${ }^{6}$ In this section we do not specify the region we are referring to (since the same description holds symmetrically for both regions). 
capital is required for each manufacturing firm, the total number of firms / varieties, denoted by $n$, is always equal to the total private capital:

$$
n=K
$$

\section{Investment sector}

In the investment sector prevails perfect competition. The technology available to produce investment goods requires only the use of labour. The construction of 1 unit of capital (a new licence) requires $a_{I}$ units of $L$. Under the assumption of perfect competition, the price of one unit of capital is given by $p_{K}=a_{I} w_{I}$.

\section{Government}

Public policy can affect production in the manufacturing sector, via its impact on factors productivity. The government uses tax revenues to purchase capital goods to use in the production of freely available public services (health services, schooling, training on the job). The Government technology involves a requirement of 1 unit of capital for each unit of public service. ${ }^{7}$

This way of modelling public policy adds two forces potentially driving industrial location. The government competes with manufacturers on the demand side of the capital market: the presence of government purchasing investment goods reduces the amount of capital available to private agents. As for the use that the government does of purchased goods, we assume that they positively impact on workers productivity.

In general, one could assume that public services affect labour productivity in all sectors of the economy. As our main focus is the impact of public policy on industrial location, we assume that labour productivity in the agricultural sector is left unchanged by improvements in publicly provided services. On the other hand, the free provision of productive public services has the effect of lowering the labour input requirements $a_{M}$ and $a_{I}{ }^{8}$

More formally, we assume that the relationships $a_{I}=f(H)$ and $a_{M}=g(H)$ are monotonically decreasing, positive and definite in the relevant range $H \geq 0$, where $H$ represents the provision of public services.

\footnotetext{
7 We could assume that production of public services requires also a labour input but we leave the study of the consequences of this complication for future work.

8 Thus as far as the manufacturing sector is concerned it is possible to identify a direct favourable effect on variable input costs (via $a_{M}$ ) and an indirect favourable effect on fixed costs (via $\left.a_{I}\right)$.
} 


\section{Consumption}

Consumers in both regions have Cobb-Douglas preferences over the homogeneous agricultural good and a quantity index that is a CES function of the varieties of manufactured goods. The exponents of the agricultural good and of manufactures - and hence the invariant shares of income devoted to the agricultural good and to manufactures - are $(1-\mu)$ and $\mu$, respectively. The constant elasticity of substitution between the manufactured varieties is denoted by $\sigma>1$; the lower $\sigma$, the greater the consumers' taste for variety. Public services also enter in the utility function as a third component with a constant elasticity denoted by $0<\theta \leq 1$. That is,

$$
U=C_{A}^{1-\mu} C_{M}^{\mu} H^{\theta}
$$

where $C_{A}$ and $C_{M}$ are, respectively, consumption of the agricultural good and consumption of the composite of manufacturing goods.

\section{Factors Supply}

\section{$\underline{\text { Labour }}$}

There is, in total, a fixed number $L_{W}$ of workers. Each worker supplies a unit of labour per period. Labour is immobile between regions but instantaneously mobile between sectors within a region. Perfect intraregional mobility of labour ensures the equalisation of the wage rate among sectors:

$$
w_{A}=w_{M}=w_{I}=w
$$

Henceforth we denote $s_{L}$ the (fixed) share of workers located in the North

\section{$\underline{\text { Capital }}$}

The supply of new capital goods corresponds to the output of the investment goods sector

$$
Q_{K}=I+\tilde{I}=\frac{L_{I}+\tilde{L}_{I}}{a_{I}}
$$

where $I$ and $\tilde{I}$ represents, respectively, private and public investment and $L_{I}$ and $\tilde{L}_{I}$ are the corresponding labour units required for production. 
Since each manufacturer requires 1 unit of capital, the total number of firms always equals total private capital. If we denote by $\lambda$ the share of private capital located and used in region $N$, the number of varieties produced in region $r(r=N, S)$ is defined by

$$
n_{N}=\lambda n_{W}=\lambda K_{W} \text { and } n_{S}=(1-\lambda) n_{W}=(1-\lambda) K_{W}
$$

Agricultural goods and investment goods are traded costless. On the other hand, transport costs for manufacturers take an "iceberg" form: if 1 unit is shipped between the regions only $1 / T$ arrives at destination whereas $(T-1) / T$ "melts" along the way, where $T \geq 1$. We use the notion of "trade freeness', defined as $\phi \equiv T^{1-\sigma}$ where $0<\phi \leq 1$, with $\phi=1$ representing no trade cost with trade cost becoming prohibitive as $\phi \rightarrow 0$.

\section{Short-run general equilibrium}

We first characterize a short-run equilibrium contingent on the given overall capital stock $\left(K_{W}+H_{W}\right)$ and on the given regional allocation of private capital $\lambda$. In a short-run general equilibrium all markets are in equilibrium.

With no agricultural transport costs, the equilibrium agricultural price is the same in both regions. Since competition results in zero agricultural profits, the equilibrium nominal wage of workers is equal to the agricultural product price and is therefore always the same in both regions. Setting the wage (agricultural price) equal to $1, p_{A}=w=1$, it becomes the numeraire in terms of which other prices are defined.

Given the definition of unitary price for capital, in the investment sector we have that $p_{K}=w a_{I}=a_{I}$. From the equilibrium condition for the investment market, it follows $F=p_{K}=a_{I}$.

Facing a wage of 1 (perfect intraregional mobility of labour ensures the equalisation of the wage rate between sectors), each firm has a marginal cost of $a_{M}$. Given the beliefs attributed to a firm in the Dixit-Stiglitz model, each firm $i$ maximises profit on the basis of a perceived price elasticity of $-\sigma$. Considering that the indirect demand function is: 


$$
p_{M, i}=\frac{c_{i}^{-\frac{1}{\sigma}}}{\sum_{i=1}^{n} c_{i}^{\frac{\sigma-1}{\sigma}}} E
$$

Under the assumption of symmetric behaviour, each firm $i$ sets the same local (mill) price $p_{M}$ for its variety, given by

$$
p_{M}=\frac{\sigma}{\sigma-1} a_{M}
$$

Note that from (2), public expenditures affect the price level of manufacturing goods, via its impact on $a_{M}$.

The greater is the consumer's taste for variety (i.e., the lower $\sigma$ ), the lower is the degree of competition and the higher is the excess of price over marginal cost. Given the transport cost, the effective price paid by consumers for a variety produced in the other region is $p_{M} T$.

Short-run general equilibrium requires that each firm meets the demand for its variety. For a variety produced in region $r$, we have:

$$
x_{r}^{i}=d_{r}^{i}
$$

where $d_{r}^{i}$ is the demand for each variety in region $r$. From (4), the short-run equilibrium operating profit per variety in region $r$ is

$$
\pi_{r}=p_{M}^{r} x_{r}^{i}-a_{M}^{r} x_{r}^{i}=\frac{p_{M}^{r} x_{r}^{i}}{\sigma}=\frac{a_{M}^{r}}{\sigma-1} x_{r}^{i}
$$

This profit per variety constitutes the regional profit or rental per unit of capital.

Total ("world") income (gross of taxation), denoted by $Y_{W}$, comprises wages and profits and is invariant over time.

Adding the government sector to the model, total expenditure in consumption corresponds to total income, minus total investment ("world private spending in new capital"), $L_{W}^{I}=L_{S}^{I}+L_{N}^{I}$, and public expenditures in investment goods, $\tilde{L}_{W}^{I}=\tilde{L}_{S}^{I}+\tilde{L}_{N}^{I}$ : 


$$
E_{W}=Y_{W}-L_{W}^{I}-\tilde{L}_{W}^{I}
$$

There are different alternatives for the tax base assumed to finance public purchases of investment goods. We assume that productive public services are financed taxing residents' income of each region. With balanced government budgets:

$$
\tilde{L}_{N}^{I}=s_{H} \tilde{L}_{W}^{I}=\tau_{N} Y_{N} \text { and } \tilde{L}_{S}^{I}=\left(1-s_{H}\right) \tilde{L}_{W}^{I}=\tau_{S} Y_{S}
$$

where $s_{H}$ is the share of public expenditures financed by residents in the north.

In the presence of regional governments purchasing investment goods, the price of manufacturing goods in each region depends upon regional productive services $H_{r}$ :

$$
p_{M}^{N}=p \quad \text { and } \quad p_{M}^{S}=p h
$$

where $h=\frac{g\left(H_{S}\right)}{g\left(H_{N}\right)}$ and where $\frac{\partial h}{\partial H^{S}} \leq 0$. That is, the higher the provision of public services in the south - as compared to the north - the lower the relative price of manufacturing goods produced in the south.

Total expenditure on the agricultural product is $(1-\mu) E_{W} \cdot{ }^{9}$ Expenditure on manufacturers is $\mu E_{W}$. Since, from (6), profit equals the value of sales times $1 / \sigma$, the total profit received by capitalists is defined by:

$$
\Pi_{W}=\frac{\mu}{\sigma} E_{W}
$$

Therefore, given the wage of 1 , total ("world") income, comprising wages and profits, is

$$
Y_{W}=L_{W}+\frac{\mu}{\sigma} E_{W}
$$

Total expenditure corresponds to

\footnotetext{
9 The no-black hole condition requires total expenditure on the agricultural good to exceed agricultural production in each region taken singularly even in the case of complete agglomeration of the industrial activity in one of them. That is, $(1-\mu) E_{W}>\max \left\{s_{L} L ;\left(1-s_{L}\right) L\right\}$.
} 


$$
E_{W}=\frac{\sigma}{\sigma-\mu}\left(L_{W}-L_{W}^{I}-\tilde{L}_{W}^{I}\right)
$$

Since all capitalists have the same regional allocation of their capital, each receives the average profit. Given that all profits are repatriated to capital owners, the regional expenditures are

$$
\begin{gathered}
E_{N}=s_{L} L_{W}+s_{K} \frac{\mu}{\sigma} E_{W}-s_{I} L_{W}^{I}-s_{H} \tilde{L}_{W}^{I} \\
E_{S}=\left(1-s_{L}\right) L_{W}+\left(1-s_{K}\right) \frac{\mu}{\sigma} E_{W}-\left(1-s_{I}\right) L_{W}^{I}-\left(1-s_{H}\right) \tilde{L}_{W}^{I}
\end{gathered}
$$

where $E_{r}$ is the nominal expenditure in region $r, s_{L}$ is the share of workers located in the north, $s_{I}$ is the share of investment undertaken by capital owners in the north and $s_{K}$ is the share of capital owned by capitalists living in the north.

From equations (9) and (10) region N's share in total expenditure $s_{E} \equiv E_{N} / E_{W}$ can be expressed as

$$
s_{E}=\frac{\left[s_{L} \sigma+\left(s_{K}-s_{L}\right) \mu\right] L_{W}-\left\{\left[s_{I} \sigma+\left(s_{K}-s_{I}\right) \mu\right] L_{W}^{I}+\left[s_{H} \sigma+\left(s_{K}-s_{H}\right) \mu\right] \tilde{L}_{W}^{I}\right\}}{\sigma\left(L_{W}-L_{W}^{I}-\tilde{L}_{W}^{I}\right)}
$$

From a typical assumption of the footloose capital model according to which the share of capital owned by capitalists in the north is invariant, it follows $s_{I}=s_{K}=$ constant.$^{10}$ Equation (12) reduces to

$$
s_{E}=\frac{\left[s_{L} \sigma+\left(s_{K}-s_{L}\right) \mu\right] L_{W}-\left\{s_{K} \sigma L_{W}^{I}+\left[s_{H} \sigma+\left(s_{K}-s_{H}\right) \mu\right] \tilde{L}_{W}^{I}\right\}}{\sigma\left(L_{W}-L_{W}^{I}-\tilde{L}_{W}^{I}\right)}
$$

The regional manufacturing price indices facing consumers are given by

$$
G_{N}=\left[n_{N} p^{1-\sigma}+n_{S} p^{1-\sigma} T^{1-\sigma} h^{1-\sigma}\right]^{\frac{1}{1-\sigma}}=\Delta_{N}^{\frac{1}{1-\sigma}} n^{\frac{1}{1-\sigma}} p
$$
necessarily equal to the capital located and used in that region, that is, $s_{K}=\lambda$. Moreover, the share of investment changes with the share of capital employed in the north. 


$$
G_{S}=\left[n_{N} p^{1-\sigma} T^{1-\sigma}+n_{S} p^{1-\sigma} h^{1-\sigma}\right]^{\frac{1}{1-\sigma}}=\Delta_{S}^{\frac{1}{1-\sigma}} n^{\frac{1}{1-\sigma}} p
$$

where $\Delta_{N} \equiv \lambda+\phi(1-\lambda) z, \Delta_{S} \equiv \phi \lambda+(1-\lambda) z$ and $z \equiv h^{1-\sigma}$, with $\frac{\partial z}{\partial H_{S}} \geq 0$

With any barrier to trade and symmetric provision of public services, $z=1$, the cost-of-living is lower, and the real incomes of both workers and resident capitalists are higher, in the region with the larger manufacturing sector (i.e., for $\phi<1, G_{N}<G_{S}$ iff $\lambda>1 / 2$ ). Increasing $z$ could reverse this inequality, since $G_{N}<G_{S}$ iff $\lambda>z /(1+z)$.

The demand for a variety produced in region $N$ is

$$
d_{N}=\left(\mu E_{N} G_{N}^{\sigma-1}+\mu E_{S} G_{S}^{\sigma-1} \phi\right)\left(p_{M}^{N}\right)^{-\sigma}=\left[s_{E} G_{N}^{\sigma-1}+\left(1-s_{E}\right) G_{S}^{\sigma-1} \phi\right]\left(p_{M}^{N}\right)^{-\sigma} \mu E_{W}
$$

and the demand for a variety produced in region $S$ is

$$
d_{S}=\left(\mu E_{N} G_{N}^{\sigma-1} \phi+\mu E_{S} G_{S}^{\sigma-1}\right)\left(p_{M}^{S}\right)^{-\sigma}=\left[s_{E} G_{N}^{\sigma-1} \phi+\left(1-s_{E}\right) G_{S}^{\sigma-1}\right]\left(p_{M}^{S}\right)^{-\sigma} \mu E_{W}
$$

From (5), (14), (15), (16) and (17):

$$
\begin{aligned}
& x_{N}=d_{N}=\left(\frac{s_{E}}{\Delta_{N}}+\frac{1-s_{E}}{\Delta_{S}} \phi\right) \frac{\mu E_{W}}{n p} \\
& x_{S}=d_{S}=\left(\frac{s_{E}}{\Delta_{N}} \phi+\frac{1-s_{E}}{\Delta_{S}}\right) \frac{\mu E_{W}}{n p z^{\frac{\sigma}{1-\sigma}}}
\end{aligned}
$$

From (1), (6), (18) and (19), the short run equilibrium profits per variety / per unit of capital are:

$$
\begin{aligned}
& \pi_{N}=\left(\frac{s_{E}}{\Delta_{N}}+\frac{1-s_{E}}{\Delta_{S}} \phi\right) \frac{\mu E_{W}}{\sigma K_{W}} \\
& \pi_{S}=\left(\frac{s_{E}}{\Delta_{N}} \phi+\frac{1-s_{E}}{\Delta_{S}}\right) z \frac{\mu E_{W}}{\sigma K_{W}}
\end{aligned}
$$

The value of a unit of capital located in region $r$ at time $t$ is 


$$
v_{r}=\sum_{t=1}^{\infty} \frac{\pi_{r}^{e}}{(1+\rho)^{t}(1+\delta)^{t}}=\frac{\pi_{r}^{e}}{\rho+\delta+\rho \delta}
$$

where $\pi_{r}^{e}$ is the expected profit per unit of capital at time $t, \rho$ is a discount rate and $\delta$ is the depreciation rate. Equation (22) is a discrete time approximation of the corresponding expression used in Baldwin (1999, p. 260).

\section{Long-run equilibrium}

A long-run equilibrium involves the equalisation between the value of an additional unit of capital and its construction / replacement cost. ${ }^{11}$ The former depends on where the manufacturing sector is located: it is uniform between regions at the interior equilibrium and is larger at the Core in a full agglomeration equilibrium. The latter depends on where the investment goods sector is located: assuming that the investment goods sector agglomerates where capital production is less costly, the following "location conditions" can be formulated:

$$
\begin{array}{ccc}
v_{N}^{*}=v_{S}^{*}=\hat{a}_{I} & \text { for } & 0<\lambda^{*}<1 \\
v_{N}^{*}<v_{S}^{*}=\hat{a}_{I} & \text { for } & \lambda^{*}=0 \\
v_{S}^{*}<v_{N}^{*}=\hat{a}_{I} & \text { for } & \lambda^{*}=1
\end{array}
$$

where $\hat{a}_{I} \equiv \min \left(a_{I}^{N}, a_{I}^{S}\right)$.

We consider first the long-run equilibrium location of the investment goods sector. It is possible to envisage two cases depending on in which region the provision of public services is higher that corresponds, in our model, to producing capital more efficiently:

case a) $H_{S}>H_{N}$. The investment sector is agglomerated in the south, $\hat{a}_{I}=a_{I}^{S}=f\left(H_{S}\right)$.

case b) $H_{N}>H_{S}$. The investment sector is agglomerated in the north, $\hat{a}_{I}=a_{I}^{N}=f\left(H_{N}\right)$.

In a long-run equilibrium investment should be at least enough to reintegrate capital depreciation $I_{W}^{*} \geq \delta K_{W}^{*}$ and $\tilde{I}_{W}^{*} \geq \delta H_{W}$. Assuming $I_{W}^{*}=\delta K_{W}^{*}$ and $\tilde{I}_{W}^{*}=\delta H_{W}$, after substituting (3) into (9), we obtain:

\footnotetext{
${ }^{11}$ We assume, as a first approximation, perfect capital mobility so that an equilibrium, if stable, is immediately realised.
} 


$$
\frac{E_{W}^{*}}{K_{W}^{*}}=\frac{\sigma}{\sigma-\mu}\left\{\frac{L_{W}}{K_{W}^{*}}-\delta \widehat{a}_{I}\left(\frac{H_{W}+K_{W}^{*}}{K_{W}^{*}}\right)\right\}
$$

Moreover from (8), (22) and (23), taking into account that in a long-run equilibrium expectations are always realised, it follows:

$$
\frac{\mu E_{W}^{*}}{\sigma K_{W}^{*}}=(\rho+\delta+\rho \delta) \hat{a}_{I}
$$

Using (24) and (25), we get

$$
\frac{L_{W}-\delta \widehat{a}_{I} H_{W}}{K_{W}^{*}}=[(\sigma-\mu)(\rho+\delta+\rho \delta)+\mu \delta] \frac{\widehat{a}_{I}}{\mu}
$$

that is,

$$
K_{W}^{*}=\frac{\mu\left(L_{W}-\delta \hat{a}_{I} H_{W}\right)}{[(\sigma-\mu)(\rho+\delta+\rho \delta)+\mu \delta] \hat{a}_{I}}
$$

which gives the long-run equilibrium level of the capital stock (corresponding to the total number of manufacturing firms).

In studying the impact of changes in the provision of public goods on the long-run equilibrium, we need to take into account where the investment sector is agglomerated. That is, whether the longrun equilibrium is characterised by case a) or case b). For example, considering an increase in the provision of public services in the south, the effect on $K_{W}^{*}$ is

$$
\frac{\partial K_{W}^{*}}{\partial H_{S}}=-\frac{\mu\left(\delta+\frac{f^{\prime}\left(H_{S}\right)}{f\left(H_{S}\right)^{2}} L_{W}\right)}{(\sigma-\mu)(\rho+\delta+\rho \delta)+\mu \delta}<0
$$

when case a) prevails. It can be easily checked that

$$
\frac{\partial K_{W}^{*}}{\partial H_{S}}>0 \text { for }\left|f^{\prime}\left(H_{S}\right)\right|>\delta \frac{f\left(H_{S}\right)^{2}}{L_{W}}>0
$$

That is, when its effect on the labour productivity in the investment goods sector is sufficiently large, an increase in the provision of public services enlarges the overall stock of private capital. 
On the other hand, the effect on $K_{W}^{*}$ of an increase in $H_{S}$ is

$$
\frac{\partial K_{W}^{*}}{\partial H_{S}}=-\frac{\mu \delta}{(\sigma-\mu)(\rho+\delta+\rho \delta)+\mu \delta}<0
$$

when case b) prevails. That is, in the absence of any effect on labour productivity in the investment sector, an increase in the provision of public services reduces the stock of private capital.

Now we turn to the question of how changes in the provision of public services affect the relative sizes of the manufacturing sector in the two regions, that is, the regional allocation of private capital, $\lambda$.

At the interior equilibrium $\pi_{N}^{*}=\pi_{S}^{*}=\pi^{*}$. Equating (20) and (21), it follows

$$
\lambda^{*}=\frac{1}{2}+z \frac{(1-\phi)(1+\phi)}{(1-z \phi)(z-\phi)}\left(s_{E}^{*}-\frac{1}{2} \frac{(1+z \phi)(z-\phi)}{(1-\phi)(1+\phi) z}\right)
$$

where $0<\lambda^{*}<1$ for $\phi \frac{z-\phi}{1-\phi^{2}}<s_{E}^{*}<\frac{1}{z} \frac{z-\phi}{1-\phi^{2}} .{ }^{12}$

within this range:

$$
\begin{aligned}
& \lambda^{*}>\frac{1}{2} \text { for } s_{E}^{*}>\frac{1}{2} \frac{(1+z \phi)(z-\phi)}{(1+z)\left(1-\phi^{2}\right)} \\
& \lambda^{*}<\frac{1}{2} \text { for } s_{E}^{*}<\frac{1}{2} \frac{(1+z \phi)(z-\phi)}{(1+z)\left(1-\phi^{2}\right)}
\end{aligned}
$$

with $\frac{1}{2} \frac{(1+z \phi)(z-\phi)}{(1+z)\left(1-\phi^{2}\right)} \geq(<) \frac{1}{2}$ for $z \geq(<) 1$.

From (12) and (26) $s_{E}^{*}$ is given by:

$$
s_{E}^{*}=\frac{s_{K} \mu \rho(1+\delta)\left(L_{W}-\delta \widehat{a}_{I} H_{W}\right)+[(\sigma-\mu)(1+\delta) \rho+\sigma \delta]\left(s_{L} L_{W}-s_{H} \delta \widehat{a}_{I} H_{W}\right)}{\sigma(\rho+\delta+\rho \delta)\left(L_{W}-\delta \widehat{a}_{I} H_{W}\right)}
$$

\footnotetext{
${ }^{12}$ Note that the condition $\phi<z<\phi^{-1}$ is necessary condition for this inequality to hold. That is, the two regions should not differ too much in terms of provisions of public services within their territory.
} 
The impact of $H_{S}$ on the regional distribution of consumption expenditures, $s_{E}^{*}$ and $\left(1-s_{E}^{*}\right)$, is given by

$$
\begin{aligned}
& \frac{\partial s_{E}^{*}}{\partial H_{S}}=\frac{\partial \tilde{L}_{W}^{I}}{\partial H_{S}}\left(s_{L}-s_{H}\right) \frac{[(\sigma-\mu)(1+\delta)+\sigma \delta] L}{\left(L-\delta \hat{a}_{I} H_{W}\right)^{2}(\rho+\delta+\rho \delta)} \geq(<) 0 \quad \text { with } \\
& \frac{\partial s_{E}^{*}}{\partial H_{S}} \geq(<) 0 \text { for } \frac{\partial \tilde{L}_{W}^{I}}{\partial H_{S}}\left(s_{L}-s_{H}\right) \geq(<) 0
\end{aligned}
$$

That is, the effect of an increase in the provision of productive public services on $s_{E}^{*}$ and $\left(1-s_{E}^{*}\right)$ depends on the combined signs of two expressions: the derivative of public expenditures in investment goods, $\tilde{L}_{W}^{I}=\delta \widehat{a}_{I} H_{W}$, with respect to $H_{S}$ and the difference between $s_{L}$ and $s_{H}$.

As for the first expression, if case a) prevails, it corresponds to $\partial \tilde{L}_{W}^{I} / \partial H_{S}=f^{\prime}\left(H_{S}\right) H_{W}+f\left(H_{S}\right)$, which is negative when $f^{\prime}\left(H_{S}\right)$ is sufficiently large in absolute value. That is, $\partial \tilde{L}_{W}^{I} / \partial H_{S}<0$ for $\left|f^{\prime}\left(H_{S}\right)\right|>f\left(H_{S}\right) / H_{W}$. On the other hand, if case b) prevails $\partial \tilde{L}_{W}^{I} / \partial H_{S}=\delta f\left(H_{N}\right)>0$, that is, this derivative is always positive.

Regarding the difference between $s_{L}$ (interpreted as a measure of the fiscal capacity of the north compared to the south) and $s_{H}$ (the share of public expenditures financed by residents in the north), the closer the burden of taxation on the north compared with its contributive capacity, the smaller is the effect of an increase in the provision of productive public services on the shares of total expenditures, becoming nil at $s_{L}=s_{H}$. Moreover, starting from a value of $s_{H}$ below $s_{L}$, such an effect is reversed as $s_{H}$ is increased above $s_{L}$. For example, assuming $\partial \tilde{L}_{W}^{I} / \partial H_{S}>0-$ which is true if the impact on productivity of an increase in the provision of public services is not too large $\partial s_{E}^{*} / \partial H_{S}$ switches from a positive to a negative sign.

In summary, provided that the two regions equilibrate the financing of public expenditures with their relative contributive capacity $\left(s_{L} \approx s_{H}\right)$, the effect of providing public services on the expenditure shares is negligible. On the other hand, if northern tax payers are taxed by less than their contributive capacity, then if the effect on productivity in the investment goods sector of such provision is small, south could suffer from a reduction in the size of the local market. 
Finally, the impact of the provision of productive public services on the equilibrium industrial location can be studied looking at the sign of the following derivative:

$$
\frac{\partial \lambda^{*}}{\partial H_{S}}=-\frac{\phi}{(1-\phi z)^{2}}\left[1-\frac{\left(z^{2}-1\right)\left(1-\phi^{2}\right)}{(z-\phi)^{2}} S_{E}^{*}\right] \frac{\partial z}{\partial H_{S}}+z \frac{1-\phi^{2}}{(1-\phi z)(z-\phi)} \frac{\partial s_{E}^{*}}{\partial H_{S}}
$$

It is possible to identify neatly two effects that an increase in $H_{S}$ could exert on the location of the manufacturing sector:

1) The demand effect $=z \frac{1-\phi^{2}}{(1-\phi z)(z-\phi)} \frac{\partial s_{E}^{*}}{\partial H_{S}}$ according to which the provision of productive public services in the south affects $\lambda^{*}$ and $\left(1-\lambda^{*}\right)$ via a change in the relative market size. Since $\phi<z<\phi^{-1}$ and $\phi<1$, the sign of the demand effect corresponds to the sign of $\frac{\partial s_{E}^{*}}{\partial H_{S}}$. Therefore, as long as the effect on productivity in the investment goods sector of an increase in $H_{S}$ is small, the demand effect is positive on $\lambda^{*}$ and negative on $\left(1-\lambda^{*}\right)$.

2) The productivity effect $=-\frac{\phi}{(1-\phi z)^{2}}\left[1-\frac{\left(z^{2}-1\right)\left(1-\phi^{2}\right)}{(z-\phi)^{2}} s_{E}^{*}\right] \frac{\partial z}{\partial H_{S}}$ according to which the provision of productive public services in the south affects $\lambda^{*}$ and $\left(1-\lambda^{*}\right)$ via its effect on the labour productivity in the southern manufacturing sector. Since the term in the square brackets is positive for any $0 \leq s_{E}^{*} \leq 1$, the productivity effect is negative on $\lambda^{*}$ and positive on $\left(1-\lambda^{*}\right)$.

When both the demand effect and the productivity effect are different from zero, $\frac{\partial \lambda *}{\partial H_{S}}<0\left(\frac{\partial\left(1-\lambda^{*}\right)}{\partial H_{S}}>0\right)$ when:

$\frac{\partial s_{E}^{*}}{\partial H_{S}}<\frac{\partial z}{\partial H_{S}} \frac{\phi(z-\phi)}{z(1-\phi z)\left(1-\phi^{2}\right)}\left[1-\frac{\left(z^{2}-1\right)\left(1-\phi^{2}\right)}{(z-\phi)^{2}} S_{E}^{*}\right]$

That is, when $\frac{\partial s_{E}^{*}}{\partial H_{S}}$ is negative, zero or positive but sufficiently small. 
In words, an increase in $H_{S}$ can lead to a higher relative size of the southern manufacturing market by relocation of firms from the north to the south - even in the presence of a non favorable demand effect as long as this effect is not too large.

The latter result tells us that policy measures aimed at enhancing labour productivity of southern manufacturing firms will be effective only if the North participates to the financing of such policies. If the South is "left alone" (that is, if public services are financed solely by income of residents in the South), then the demand effect of an increase in $H_{S}$ will probably prevail. On the other hand, if the government sets $s_{H}$ at sufficiently high value, letting northern tax payers contribute on the basis of their capacity $\left(s_{L}\right)$, then the demand effect of public expenditures will be more than offset by the productivity effect.

\section{Welfare analysis}

The indirect utility of a representative household living respectively in the North and in the South corresponds to

$$
\begin{gathered}
V_{N}=\left((1-\mu) \frac{E_{N}}{\bar{P}_{N} L_{N}}\right)^{1-\mu}\left(\mu \frac{E_{N}}{\bar{P}_{N} L_{N}}\right)^{\mu} H_{N}{ }^{\theta}=\vartheta \frac{E_{N}}{G_{N}^{\mu} L_{N}} H_{N}{ }^{\theta} \\
V_{S}=\left((1-\mu) \frac{E_{S}}{\bar{P}_{S} L_{S}}\right)^{1-\mu}\left(\mu \frac{E_{S}}{\bar{P}_{S} L_{S}}\right)^{\mu} H_{S}{ }^{\theta}=\vartheta \frac{E_{S}}{G_{S}^{\mu} L_{S}} H_{S}{ }^{\theta}
\end{gathered}
$$

where $\bar{P}_{r}=p_{A}^{1-\mu} G_{r}^{\mu}$ is the perfect price index in region $r(r=N, S)$, which takes into account agricultural prices, $E_{r} / L_{r}$ is the expenditure per household in region $r$, and $\vartheta \equiv(1-\mu)^{1-\mu} \mu^{\mu}$.

For the sake of simplicity, we assume that the two regions are symmetric $s_{L}=s_{K}=\frac{1}{2}$ and that $S_{L}=s_{H}$. That is, we rule out by assumption the demand effect on the interior equilibrium value of $\lambda$. If follows $s_{E}=\frac{1}{2}$.

A change in $H_{S}$ affects $V_{N}$ only indirectly via $G_{N}$ or via $E_{N}$. That is, 
$\frac{\partial V_{N}}{\partial H_{S}}=\frac{\partial E_{N}}{\partial H_{S}} \frac{V_{N}}{E_{N}}-\mu \frac{\partial G_{N}}{\partial H_{S}} \frac{V_{N}}{G_{N}}$

Consider $G_{N}=p \Delta_{N}^{\frac{1}{1-\sigma}} K_{W}^{\frac{1}{1-\sigma}}$ first: an increase in the provision of public services in the South determines the following change in the North price index of manufacturing goods:

$$
\frac{\partial G_{N}}{\partial H_{S}}=-\frac{G_{N}}{\sigma-1}\left(\frac{\partial \Delta_{N}}{\partial H_{S}} \Delta_{N}^{\sigma}+\frac{\partial K_{W}}{\partial H_{S}} K_{W}^{\sigma}\right)
$$

At the interior equilibrium corresponding to $s_{E}=\frac{1}{2}, \quad \Delta_{N}=\frac{1}{2}\left(1-\phi^{2}\right) \frac{z}{z-\phi} \quad$ and $\frac{\partial \Delta_{N}}{\partial z}=-\frac{1}{2} \frac{1-\phi^{2}}{(z-\phi)^{2}} \phi<0$. It follows that: if $\frac{\partial K_{W}}{\partial H_{S}}<0$ or $\frac{\partial K_{W}}{\partial H_{S}}>0$, but sufficiently small, then $\frac{\partial G_{N}}{\partial H_{S}}>0$. In general, $\frac{\partial G_{N}}{\partial H_{S}}>0$ when $\frac{\partial K_{W}}{\partial H_{S}}<-\frac{\partial \Delta_{N}}{\partial H_{S}}\left(\frac{\Delta_{N}}{K_{W}}\right)^{\sigma}$.

That is, since part of the production of manufacturing goods has moved to the South, their consumption is more expensive for the residents in the North because of transport costs. Moreover, if public expenditure involves a reduction in the size of the overall economy - that is, the number of manufacturing firms becomes smaller - the Northern price index increases and welfare decreases. If the size of the overall economy increases, instead, the effect on the price Index is negative if the increase of $K_{W}$ is small and it is positive if such increase is sufficiently large.

Consider now $E_{N}=\frac{E_{W}}{2}$, where $\quad E_{W}=\frac{\sigma(\rho+\delta+\rho \delta)\left(L_{W}-\delta \hat{a}_{I} H_{W}\right)}{(\sigma-\mu)(\rho+\delta+\rho \delta)+\mu \delta}$. We have that $\frac{\partial E_{W}}{\partial H_{S}}=-\frac{\sigma(\rho+\delta+\rho \delta)(1-|\varepsilon|)}{(\sigma-\mu)(\rho+\delta+\rho \delta)+\mu \delta}<0$ (and therefore $\left.\frac{\partial E_{N}}{\partial H_{S}}<0\right)$ iff $|\varepsilon|<1$, where $\varepsilon \equiv \frac{d \widehat{a}_{I}}{d H_{S}} \frac{H_{W}}{\widehat{a}_{I}}$. That is, if the impact of a change of $H_{S}$ on productivity is small; the welfare of a representative household in the North decreases.

A change in $H_{S}$ affects $V_{S}$ both directly and indirectly via $G_{N}$ or via $E_{N}$. That is,

$$
\frac{\partial V_{S}}{\partial H_{S}}=\frac{\partial E_{S}}{\partial H_{S}} \frac{V_{S}}{E_{S}}-\mu \frac{\partial G_{S}}{\partial H_{S}} \frac{V_{S}}{G_{S}}+\theta \frac{V_{S}}{H_{S}}
$$


Consider $G_{S}=p \Delta_{S}^{\frac{1}{1-\sigma}} K_{W}^{\frac{1}{1-\sigma}}$ first: an increase in the provision of public services in the South determines the following change in the south manufacturing price index:

$\frac{\partial G_{S}}{\partial H_{S}}=-\frac{G_{S}}{\sigma-1}\left(\frac{\partial \Delta_{N}}{\partial H_{S}} \Delta_{S}^{\sigma}+\frac{\partial K_{W}}{\partial H_{S}} K_{W}^{\sigma}\right)$

At the interior equilibrium corresponding to $s_{E}=\frac{1}{2}, \quad \Delta_{S}=\frac{1}{2}\left(1-\phi^{2}\right) \frac{z}{1-z \phi} \quad$ and $\frac{\partial \Delta_{S}}{\partial z}=\frac{1}{2} \frac{1-\phi^{2}}{(z-\phi)^{2}}>0$. It follows that if $\frac{\partial K_{W}}{\partial H_{S}}>0$ or $\frac{\partial K_{W}}{\partial H_{S}}<0$, but sufficiently small in absolute value, then $\frac{\partial G_{S}}{\partial H_{S}}<0$. In general, $\frac{\partial G_{S}}{\partial H_{S}}<0$ when $\frac{\partial K_{W}}{\partial H_{S}}>-\frac{\partial \Delta_{S}}{\partial H_{S}}\left(\frac{\Delta_{S}}{K_{W}}\right)^{\sigma}$

That is, since more goods are produced in the South, consumption of manufacturing goods is cheaper for the residents in the South because they pay less for transport costs. Moreover, if public expenditure involves an increase in the size of the overall economy this effect is enhanced. If the size of the overall economy decreases but not too much the overall effect on the price Index is still negative. However, if the reduction of $K_{W}$ is sufficiently large also the price index in the south increases.

Considering now $E_{S}=\frac{E_{W}}{2}$, as before we have that $\frac{\partial E_{W}}{\partial H_{S}}<0$ (and therefore $\frac{\partial E_{S}}{\partial H_{S}}<0$ ) iff $|\varepsilon|<1$. That is, if the impact of a change of $H_{S}$ on productivity is sufficiently large, the effect on welfare of a representative household in the South is unambiguously positive. If it is sufficiently close to zero, the effect on southern welfare depends on the counterbalancing of two negative (the reduction in the overall expenditure and the reduction of the size of the overall economy) and two positive effects (the aggregation of industrial activity and the consumption of public services).

\section{Concluding remarks}

We have adopted a CC model with capital mobility where the government sector provides firms with services produced with investment goods and financed taxing the residents' income of each region. As a major contribution to the literature, our approach considers jointly two effects arising from public policy decisions on expenditures: the demand effect and the productivity effect. The 
interplay of these two effects determines the final impact of an increase in productive public spending in one region on the spatial distribution of firms. Furthermore, the latter result is influenced by the way in which tax payers of the two regions contribute to the financing of productive public expenditures. Finally, in the case of symmetric regions, the impact of an in increase productive public services is unambiguously welfare enhancing.

An important conclusion of our work is the following: assuming that productive expenditures could be used effectively to enhance factors' productivity in a backward region, policy measures aimed at reducing regional asymmetries could work only if advanced regions contribute to the financing of such policies.

\section{REFERENCES}

Baldwin R. (1999), “Agglomeration and endogenous capital”, European Economic Review 43: 253280

Baldwin R., R. Forslid, P. Martin, G.I.P. Ottaviano and F. Robert-Nicoud (2003), "Economic geography and public policy", Princeton University Press

Borck R. and M. Pflüger (2006), “Agglomeration and tax competition”, European Economic Review, 50(3): 647-68

Baldwin S. and P.R. Krugman (2004), "Agglomeration, integration and tax harmonisation", European Economic Review, 48(1): 1-23

Brakman S., Garretsen H. and C. van Marrewijk (2002), "Local competition and Agglomeration: the role of Government Spending”, CESifo Working Paper Series No. 775

Brülhart M. and F. Trionfetti (2004), "Public expenditure, specialisation and agglomeration", European Economic Review, 48: 851-71

Commendatore P. and I. Kubin (2006), “Taxation and Agglomeration”, Center for Nonlinear Dynamics in Economics and Finance (CeNDEF) Working paper 06-08, University of Amsterdam

Commendatore P., M. Currie and I. Kubin (2005), "Footloose Entrepreneurs, taxes and subsidies", The School of Economics Discussion Paper Series 0521, University of Manchester 
Dupont V. and P. Martin (2006), "Subsidies to poor regions and inequalities: some unpleasant arithmetic", Journal of Economic Geography, 6(2): 223-240

Forslid R., (1999), “Agglomeration with human and physical capital: an analytically solvable case”, Discussion Paper No. 2102, Centre for Economic Policy Research

Forslid R. and G.I.P. Ottaviano (2003), “An analytically solvable core-periphery model”, Journal of Economic Geography, 3: 229 - 240

Krugman P.R. (1991), “Increasing returns and economic geography”, Journal of Political Economy, 99: 483-499

Martin P. (1999), "Public policies, regional inequalities and growth", Journal of Public Economics 73: $85-105$

Martin, P. and G.I.P. Ottaviano (1999), "Growing locations: industry location in a model of endogenous growth", European Economic Review 43, 281-302

Martin P. and C.A. Rogers (1995), "Industrial location and public infrastructure", Journal of International Economics, 39: 335-351

Martin P., and G. I. P. Ottaviano (2001), "Growth and agglomeration", International Economic Review, 42(4): 947-968

Ottaviano G.I.P. (2001), "Monopolistic competition, trade, and endogenous spatial fluctuations", Regional Science and Urban Economics, 31: 55-77.

Samuelson P. (1954), "The transfer problem and transport costs, II: analysis of effects of trade impediments", Economic Journal 64, 264-289

Trionfetti F. (1997), "Public Expenditure and Economic Geography”, Annales d'Économie et de Statistique, 47: 101-120 